\title{
Влияние импульсного гамма-нейтронного облучения на фоточувствительность фотодиодов на базе Si с наноостровками GeSi и эпитаксиальными слоями Ge
}

\author{
(C) М.М. Иванова ${ }^{1,2}$, А.Н. Качемцев ${ }^{1}$, А.Н. Михайлов ${ }^{2}$, Д.О. Филатов ${ }^{2}$, А.П. Горшков ${ }^{2}$, \\ Н.С. Волкова ${ }^{2}$, В.Ю. Чалков ${ }^{2}$, В.Г. Шенгуров ${ }^{2, \text { Ф }}$ \\ ${ }^{1}$ Федеральный научно-производственный центр „Научно-исследовательский институт \\ измерительных систем им. Ю.Е. Седакова“, \\ 603950 Нижний Новгород, Россия \\ ${ }^{2}$ Нижегородский государственный университет им. Н.И. Лобачевского, \\ 603950 Нижний Новгород, Россия \\ ฯ E-mail: shengurov@phys.unn.ru
}

(Получена 20 июня 2017 г. Принята к печати 28 июня 2017 г.)

\begin{abstract}
Приведены результаты сравнительного исследования влияния импульсного $\gamma$-нейтронного облучения на спектры фоточувствительности $\mathrm{Si} p-n$-фотодиодов с активной областью на базе массивов самоформирующихся наноостровков $\mathrm{GeSi}$ и эпитаксиальных слоев Ge. Установлено, что облучение фотодиодов с наноостровками $\mathrm{GeSi}$ не приводит к деградации фоточувствительности в спектральной области межзонного оптического поглощения в наноостровках (диапазон длин волн 1.1-1.7 мкм). В то же время обнаружено монотонное ослабление собственной фоточувствительности $\mathrm{Si}$, а также фоточувствительности фотодиодов на базе эпитаксиальных слоев Ge с ростом дозы облучения, связанное с накоплением радиационных дефектов в матрице $\mathrm{Si}$ и в глубине эпитаксиальных слоев $\mathrm{Ge}$ соответственно.
\end{abstract}

DOI: 10.21883/FTP.2018.06.45931.8670

\section{1. Введение}

Использование оптоэлектронных межэлементных соединений существенно повышает эксплуатационные характеристики радиоэлектронного оборудования, такие как помехозащищенность, быстродействие и энергоэффективность. Однако радиационная стойкость таких устройств не в полной мере удовлетворяет потребностям современной электронной компонентной базы, применяемой в вооружениях, военной и специальной технике, к которой предъявляются требования стойкости к воздействию ионизирующих излучений. Одним из путей повышения радиационной стойкости полупроводниковых оптоэлектронных приборов (полупроводниковых лазеров, фотодетекторов, оптронов и др.) является использование в качестве материала активной области полупроводниковых приборов массивов самоформирующихся наноостровков или квантовых точек $[1,2]$. Проведенные ранее исследования влияния различных радиационных воздействий на фотолюминесценцию [3] и электролюминесценцию [4] гетероструктур с самоформирующимися наноостровками $\mathrm{GeSi}$ в матрице $\mathrm{Si}$ показали их более высокую радиационную стойкость по сравнению с аналогичными структурами на базе объемного Si. Рост радиационной стойкости связан с пространственной локализацией дырок и электронов в наноостровках $\mathrm{GeSi}$ и вблизи их гетерограницы с $\mathrm{Si}$ соответственно, что препятствует диффузии избыточных носителей заряда к центрам безызлучательной рекомбинации, связанным с радиационными дефектами в матрице $\mathrm{Si}$ [4].
В то же время исследованию влияния облучения на фотоэлектрические свойства структур с наноостровками $\mathrm{GeSi}$ в матрице $\mathrm{Si}$ уделялось недостаточное внимание. Анализ влияния облучения на фотоотклик таких структур в спектральной области длин волн $\lambda=1.3-1.55$ мкм, соответствующей окну прозрачности волоконных световодов на основе безводного кварцевого стекла (так называемый коммуникационный диапазон длин волн), представляет интерес с точки зрения возможности их использования в радиационно-стойких фотоприемниках на базе $\mathrm{Si}$ с расширенным спектральным диапазоном в инфракрасную (ИК) область.

Цель настоящей работы - сравнительное исследование влияния импульсного $\gamma$-нейтронного облучения $p-n$-фотодиодов на базе $\mathrm{Si}$ с наноостровками $\mathrm{GeSi}$ в активной области и фотодиодов на базе эпитаксиальных слоев (ЭС) $\mathrm{Ge} / \mathrm{Si}$, которые также считаются перспективными фотодетекторами коммуникационного диапазона длин волн [5], на спектры их фоточувствительности (ФЧ).

\section{2. Методика эксперимента}

Исследуемые фотодиоды с самоформирующимися наноостровками $\mathrm{GeSi}$ были изготовлены на основе $\mathrm{Si}$ $p$-n-структур с одно- и 5-слойными массивами островков, встроенными в $p-n$-переход. Структуры выращивались с использованием комбинированного метода сублимационной молекулярно-пучковой эпитаксии (СМЛЭ) Si и газофазной эпитаксии (ГФЭ) Ge при низком давлении с использованием в качестве прекурсора 
германа $\left(\mathrm{GeH}_{4}\right)$ [6]. Выбор режимов роста структур обусловливался проведенными ранее исследованиями, результаты которых обобщены в работе [7]. Структура с однослойными массивами нанооостровков $\mathrm{GeSi}$ была выращена на подложке $n^{+}-\mathrm{Si}(001)$ марки КЭС-0.01. Подложка отжигалась при температуре $T_{g}=1200^{\circ} \mathrm{C}$ в течение 20 мин. После отжига на поверхность подложки при температуре $T_{g}=650^{\circ} \mathrm{C}$ осаждался буферный слой $n^{+}$-Si толщиной $\sim 0.6$ мкм, легированный фосфором $(\mathrm{P})$ с концентрацией $\sim 5 \cdot 10^{18} \mathrm{~cm}^{-3}$. На поверхности буферного слоя при той же температуре осаждался слой $p$ $\mathrm{Si}$ толщиной $\sim 0.2$ мкм, легированный бором $(\mathrm{B})$ с концентрацией $\sim 10^{17} \mathrm{~cm}^{-3}$. Затем $T_{g}$ понижали до $600^{\circ} \mathrm{C}$, в камеру роста напускали $\mathrm{GeH}_{4}$ и выдерживали в течение 4 мин. Парциальное давление $\mathrm{GeH}_{4}$ в камере $P g$ составляло $\sim 9 \cdot 10^{-4}$ Торр. При этом $\mathrm{GeH}_{4}$ разлагался пиролитически на поверхности подложки, на которую осаждался слой Ge. Последний по механизму СтранскогоКрастанова в ходе роста трансформировался в массив наноостровков $\mathrm{GeSi}[8]$. После откачки $\mathrm{GeH}_{4}$ на поверхность массива наноостровков $\mathrm{GeSi}$ при $T_{g}=500^{\circ} \mathrm{C}$ наращивали подконтактный слой $p^{+}-\mathrm{Si}$ толщиной $\sim 0.1$ мкм, легированный бором (B) с концентрацией $\sim 10^{19} \mathrm{~cm}^{-3}$.

Структура с 5-слойным массивом наноостровков $\mathrm{GeSi}$ выращивалась на подложке $p^{+}-\mathrm{Si}(001)$ марки КДБ0.01 . Буферный слой $p^{+}-\mathrm{Si}$ толщиной $\sim 0.2$ мкм, легированный бором (В) с концентрацией $\sim 10^{19} \mathrm{~cm}^{-3}$, выращивался при $T_{g}=1000^{\circ} \mathrm{C}$. Осаждение $\mathrm{Ge}$ проводилось при $T_{g}=650^{\circ} \mathrm{C}$, время напуска $\mathrm{GeH}_{4}$ в ростовую камеру составляло $\sim 2.5$ мин. Массивы наноостровков $\mathrm{GeSi}$ разделялись спейсерными слоями $n$ $\mathrm{Si}: \mathrm{P}$ толщиной $\sim 0.1$ мкм, осажденными при $T_{g}=650^{\circ} \mathrm{C}$. Концентрация фосфора (Р) в спейсерных слоях $n-\mathrm{Si}$ составляла $\sim 2 \cdot 10^{15} \mathrm{~cm}^{-3}$. Подконтактный слой $n^{+}-\mathrm{Si}$ в этой структуре, легированный фосфором $(\mathrm{P})$ с концентраций $\sim 10^{19} \mathrm{~cm}^{-3}$, выращивался при $T_{g} \sim 500^{\circ} \mathrm{C}$.

Фотодиоды с активным слоем на базе ЭС Ge/Si формировались на подложках $n^{+}-\mathrm{Si}(001)$ марки КЭС-0.01, на которые при $T_{g} \sim 1000^{\circ} \mathrm{C}$ осаждались буферные слои $n^{+}$-Si толщиной $\sim 0.2$ мкм, легированные фосфором $(\mathrm{P})$ с концентрацией $\sim 10^{18} \mathrm{~cm}^{-3}$. На поверхность буферных слоев $n^{+}$-Si методом горячей проволоки [9] при $T_{g} \sim 350^{\circ} \mathrm{C}$ осаждались ЭС Ge толщиной $\sim 1$ мкм. Для этого в ростовую камеру напускали $\mathrm{GeH}_{4}$ до давления $p_{g}=4 \cdot 10^{-4}$ Торр, который разлагался на поверхности Та-проволоки, нагреваемой пропусканием через нее постоянного тока до $1200^{\circ} \mathrm{C}$. Слои $\mathrm{Ge}$ имели $p$-тип проводимости, фоновая концентрация дырок составляла $\sim 10^{17} \mathrm{~cm}^{-3}$. Подконтактные слои $p^{+}$-Gе формировались имплантацией ионов бора (В) с последующим отжигом при $\sim 550^{\circ} \mathrm{C}$ в течение 30 мин. Доза ионов бора (В) составляла $\sim 1.5 \cdot 10^{15} \mathrm{~cm}^{-2}$, энергия ионов $\sim 30$ кэВ. Более подробно методика выращивания ЭС $\mathrm{Ge} / \mathrm{Si}$, а также результаты исследований морфологии, кристаллической структуры, электрофизических и оптических свойств полученных ЭС и фотоэлектрических свойств фотодиодов на их основе приведены в работе [10].
На базе выращенных структур формировались мезафотодиоды с верхним омическим контактом $\mathrm{Au} / \mathrm{Pd} / \mathrm{Ti}$ c окнами для доступа возбуждающего излучения различной конфигурации: кольцеобразные контакты с внешним диаметром $\sim 350$ мкм и контактные сетки размером $900 \times 1500$ мкм. Со стороны подложки формировались сплошные омические контакты $\mathrm{Au} / \mathrm{Pd} / \mathrm{Ti}$.

Исследуемые образцы подвергались импульсному $\gamma$-нейтронному облучению. Средняя эффективная энергия сплошного спектра фотонов составляла $1.5 \mathrm{MэB}$. Средняя эффективная энергия спектра нейтронов составляла $\approx 0.8 \mathrm{MэВ} \mathrm{с} \mathrm{верхней} \mathrm{границей} \mathrm{до} 18 \mathrm{MэВ.} \mathrm{Для}$ образца с 5-слойным массивом островков интегральный поток нейтронов составил $1.0 \cdot 10^{14} \mathrm{~cm}^{-2}$, экспозиционная доза - 400 кР. Для образцов с однослойным массивом наноостровков $\mathrm{GeSi}$ и с активным слоем на базе ЭС $\mathrm{Ge} / \mathrm{Si}$ этот уровень достигался за два последовательных $\gamma-\eta$ импульса меньшей интенсивности.

Спектры ФЧ в режиме фотоэдс холостого хода образцов измерялись до и после облучений. Источником монохроматического излучения служил решеточный монохроматор МДР-2 (ЛОМО) с галогеновой лампой мощностью 100 Вт. Для построения спектров ФЧ $S$ спектры фотоэдс нормировались на относительное спектральное распределение интенсивности фотовозбуждения. Интенсивность последнего на длине волны $\sim 1$ мкм составляла $\sim 1.8 \cdot 10^{15}$ фот/( $\left.\mathrm{cm}^{2} \cdot \mathrm{c}\right)$, разрешающая способность монохроматора при ширине входной и выходной щелей 0.5 мм составляла $\sim 2.5$ мэВ.

\section{3. Результаты и обсуждение}

В спектрах ФЧ фотодиодов с наноостровками $\mathrm{GeSi}$, кроме полосы собственной ФЧ $\mathrm{Si}$ в спектральной области энергий квантов фотовозбуждения $h v>1.00-1.05$ эВ, наблюдались полосы ФЧ в области $0.70-0.75$ эВ $<h v<1.00-1.05$ эВ, обусловленной межзонным оптическим поглощением в наноостровках $\mathrm{GeSi}$ [11]. По мере увеличения дозы радиационного воздействия наблюдается снижение собственной ФЧ Si в спектральной области $h v>1.00-1.05$ эВ, в то время как $\Phi Ч$ в области межзонного поглощения островков $\mathrm{GeSi}$ остается на прежнем уровне см. (см. рисунок, $a$ ). Снижение собственной $\Phi Ч \mathrm{Si}$ может быть связано с уменьшением времени жизни неосновных носителей заряда $\tau$, которое вызвано введением дополнительных рекомбинационных уровней в запрещенной зоне $\mathrm{Si}$ в результате накопления радиационных дефектов в ходе облучения. Ввиду малого значения коэффициента собственного оптического поглощения кремния $\left(\alpha \sim 2.5 \mathrm{~cm}^{-1}\right.$ при $h v \sim E_{\mathrm{gSi}}\left(E_{\mathrm{gSi}} \sim 1.12\right.$ эB, $293 \mathrm{~K}-$ ширина запрещенной зоны $\mathrm{Si}$ )) [12], значительная часть падающего на фотодиод излучения поглощается в глубине структуры. Так, интенсивность излучения с $h v \sim 1.12$ эВ уменьшается в $e$ раз на расстоянии $\sim \alpha^{-1} \sim 4$ мм от поверхности структуры. В этих условиях значительный 

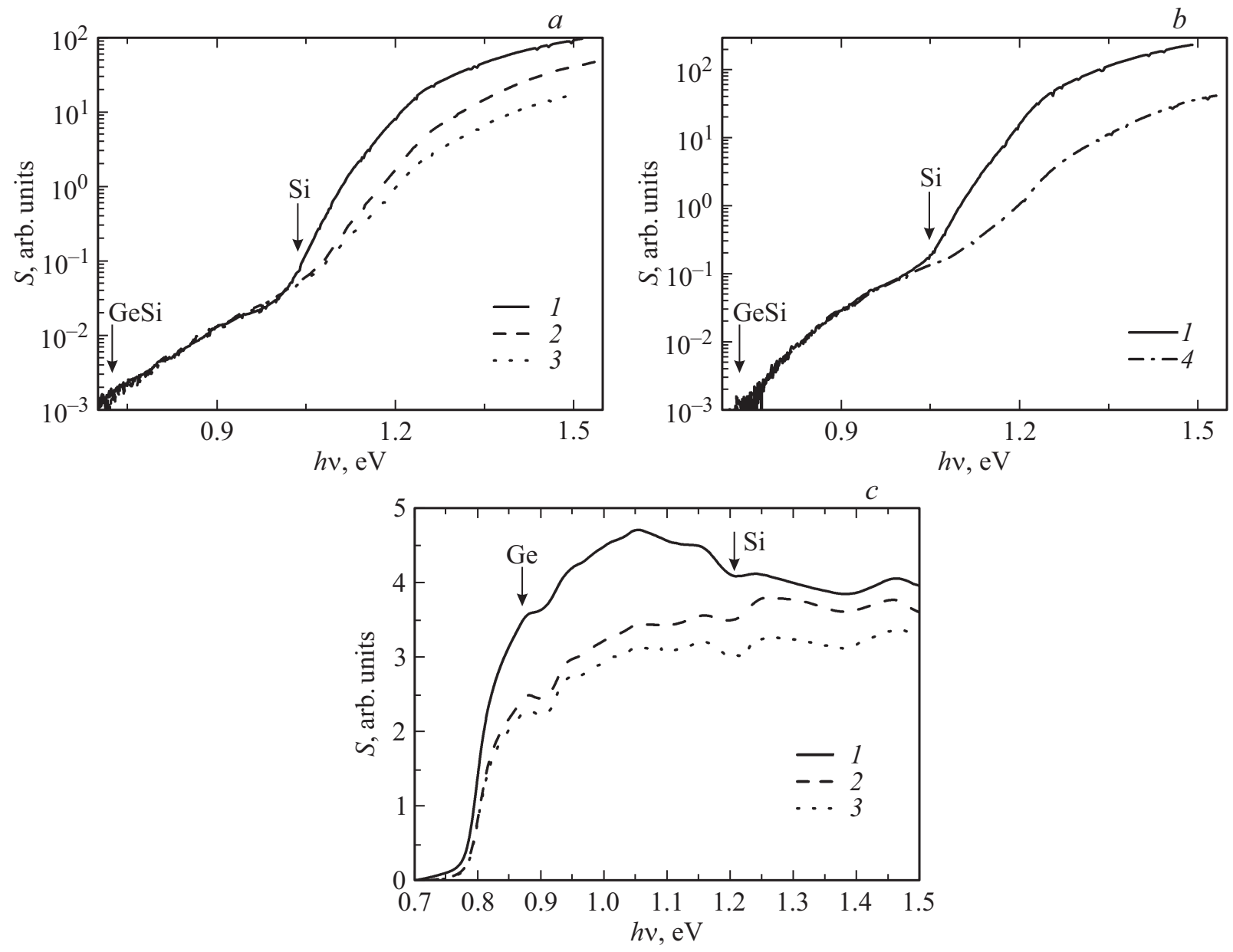

Спектры ФЧ $(300 \mathrm{~K})$ фотодиодов с однослойным $(a)$ и 5-слойным $(b)$ массивами наноостровков $\mathrm{GeSi}$ и с ЭС $\mathrm{Ge}(c)$ до и после облучений: 1 - до облучения, 2 - после облучения одним $\eta-\gamma$-импульсом; 3 - после облучения двумя последовательными $\eta-\gamma$-импульсами, 4 - после облучения $\eta-\gamma$-импульсом по уровню, соответствующему воздействию 3 . Стрелками указаны края полос собственной $Ф Ч \mathrm{Si}$, а также полос ФЧ, обусловленной межзонным оптическим поглощением в массивах наноостровков $\mathrm{GeSi}(a, b)$ и ЭС Ge $(c)$.

вклад в собственную ФЧ $\mathrm{Si}$ вносит механизм, связанный с диффузией неосновных носителей заряда из глубины структуры к границе области пространственного заряда (ОПЗ) $p-n$-перехода и дальнейшим их дрейфом в электрическом поле перехода к соответствующему контакту [13]. Спектральная зависимость собственной ФЧ Si в этом случае описывается формулой [13]

$$
S(h v) \propto \frac{\alpha(h v) L}{1+\alpha(h v) L},
$$

где $L=(D \tau)^{1 / 2}$ и $D$ - длина и коэффициент диффузии неосновных носителей в $\mathrm{Si}$ соответственно. Так как уменьшение времени жизни неосновных носителей $\tau$ уменьшает длину диффузии $L$, это вызывает увеличение доли неосновных носителей, рекомбинирующих в $\mathrm{Si}$ в процессе диффузии к границе ОПЗ $p-n$-перехода и соответственно к уменьшению доли носителей, достигших границы ОПЗ. Это в свою очередь приводит к уменьшению ФЧ фотодиодов в спектральной области собственного поглощения $\mathrm{Si}$ в соответствии с (1).
Однако процесс диффузии неосновных носителей в $\mathrm{Si}$ не оказывает влияния на ФЧ фотодиодов в низкоэнергетической области $(h v<1.05$ эВ), так как ФЧ в указанном спектральном диапазоне обусловлена межзонным оптическим поглощением в наноостровках $\mathrm{GeSi}$, расположенных в ОПЗ $p-n$-перехода. В этих условиях возникновение фотоэдс связано с эмиссией дырок из островков GeSi (по туннельному, термоактивационному, либо смешанному механизму [11]) и транспортом избыточных электронов и дырок к слоям $n^{+}$- и $p^{+}$-типа соответственно в электрическом поле $p-n$-перехода. При типичных значениях напряженности электрического поля в ОП3 $F \sim E_{g} / e_{0} w>10^{4} \mathrm{~B} / \mathrm{cm}$ (здесь $e_{0}-$ элементарный заряд, $w<1$ мкм - толщина ОПЗ $p-n$-перехода) носители в ОПЗ движутся со скоростью, близкой к скорости насыщения $v_{s} \sim 10^{7} \mathrm{~cm} / \mathrm{c}$. Оценка пролетного времени носителей через ОПЗ $p-n$-перехода в указанных условиях составляет $\tau_{d} \sim w / v_{s}<10^{-11}$ с. Данное значение существенно меньше, чем рекомбинационное время жизни носителей в $\mathrm{Si}$ вплоть до весьма значи- 
тельной концентрации радиационных дефектов. Поэтому радиационное воздействие может оказать влияние на $Ф Ч$ диодов в спектральной области межзонного поглощения в островках $\mathrm{GeSi}$ только в том случае, если дефекты генерируются непосредственно в объеме или вблизи поверхности островков. Образование радиационного дефекта в отдельном островке приводит к повышению вероятности рекомбинации фотовозбужденных носителей внутри данного островка по сравнению с вероятностью их эмиссии из островка и, следовательно, к уменьшению относительного вклада данного островка в ФЧ диода. Оценка по порядку величины времени эмиссии дырок $\tau_{e}$ из наноостровков $\mathrm{GeSi}$, сделанная в работе [11] для островков $\mathrm{GeSi}$ в $p$-n-структуре, выращенной комбинированным методом СМЛЭ-ГФЭ в условиях, аналогичных нашим, составляет $\tau_{e} \sim 10^{-7}$ с для $T=300 \mathrm{~K}$ и атомной доле $\mathrm{Ge}$ в материале островков $\mathrm{GeSi} x \sim 0.55$ [7].

В то же время вклад других островков в суммарный фототок не уменышается. Вероятность образования дефекта внутри островка весьма мала по сравнению с вероятностью генерации дефектов в $\mathrm{Si}$ ввиду малости объема островков по сравнению с объемом материала, затронутого радиационным воздействием [2], и может быть оценена как $\sim d_{\mathrm{Ge}} / x R$, где $d_{\mathrm{Ge}}-$ номинальная толщина осажденного слоя $\mathrm{Ge}$ (для многослойных массивов наноостровков $d_{\mathrm{Ge}}=d_{\mathrm{Ge} 1} N_{L}$, где $d_{\mathrm{Ge} 1}-$ номинальная толщина осажденного слоя Ge для одного слоя островков, $N_{L}$ - число слоев островков в массиве), $R$ - среднее расстояние между радиационными дефектами по глубине структуры. Так как типичные значения $d_{\mathrm{Ge} 1} \sim 1.5$ нм, как правило, $d_{\mathrm{Ge}} / x R \ll 1$. Таким образом, принимая для условий облучения, указанных выше, $R=0.5$ мкм [14], $x=0.5$, получаем для $N_{L}=5$ значение соотношения $d_{\mathrm{Ge}} / x R \sim 0.03$. Заметим, что полученная оценка по порядку величины согласуется с результатами моделирования, проведенного в работе [14].

С другой стороны, не было выявлено различий во влиянии радиационных воздействий на ФЧ диодов с одно- и 5-слойными массивами островков $\mathrm{GeSi}$ в спектральной области межзонного поглощения в островках (cp. рисунок, $a$ и $b$ ). Данный результат показывает возможность увеличения числа слоев наноостровков $\mathrm{GeSi}$ в активной области фотодиодов с целью повышения абсолютных значений ФЧ в указанном спектральном диапазоне без ущерба для радиационной стойкости приборов. Следует отметить также, что границы напряженных гетерослоев в полупроводниковых гетероструктурах являются геттерами для точечных радиационных дефектов [15]. При этом в структурах с несколькими слоями островков $\mathrm{GeSi}$ можно ожидать, что крайние слои островков будут препятствовать диффузии радиационных дефектов из буферного и покровного слоев к внутренним слоям островков $\mathrm{GeSi}$ в многослойном массиве, что можно отметить как важное потенциальное преимущество фотодетекторов на базе многослойных массивов наностровков GeSi в матрице Si.
Спектральная зависимость ФЧ фотодиода на базе ЭС $\mathrm{Ge} / \mathrm{Si}$ (см. рисунок, $c$ ) в области $h v>0.8$ эВ определяется собственным оптическим поглощением в ЭС $\mathrm{Ge}$ с доминированием прямых (вертикальных в обратном пространстве) межзонных оптических переходов. Край этой полосы при $h v \sim 0.8$ эВ соответствует переходам между точками $\Gamma_{8}$ и $\Gamma_{7}$ зоны Бриллюэна $\mathrm{Ge}$ [5]. Значительно менее интенсивная полоса ФЧ в области $h v<0.8$ эВ связана с непрямыми переходами из вершины валентной зоны в точке $\Gamma$ в $L$-долину зоны проводимости Ge. В обеих полосах ФЧ уменьшается с ростом дозы облучения, что также может быть связано с увеличением скорости рекомбинации неосновных фотовозбужденных носителей (электронов) в слое $p$-Ge вследствие накопления радиационных дефектов в ходе облучения, как и в случае собственной $Ф Ч \mathrm{Si}$ в диодах с наноостровками $\mathrm{GeSi}$. Заметим, что уменьшение ФЧ с ростом дозы облучения имеет тенденцию к насыщению. Данный эффект может быть связан с тем, что, как было установлено в работе [10], слой $p$-Ge в исследуемых диодах не был полностью обеднен при нулевом внешнем напряжении на контактах. В этих условиях ФЧ в спектральной области $h v>0.8$ эВ частично обусловлена диффузией неосновных носителей (электронов) из квазинейтральной области слоя $p$-Ge, где они генерируются к границе ОП3 анизотипного гетероперехода $n^{+}-\mathrm{Si} / p-\mathrm{Ge}$, и вновь справедливо соотношение (1). Оценка диффузионной длины неосновных носителей (электронов) $L_{n}$ в слоях $p$-Ge в фотодиодах, исследованных в данной работе, составляет $\sim 0.1$ мкм [10]. С увеличением дозы облучения имеет место неравенство $L_{n} \ll w_{\mathrm{Ge}}$, где $w_{\mathrm{Ge}}-$ часть ОПЗ гетероперехода $n^{+}-\mathrm{Si} / p-\mathrm{Ge}$, приходящаяся на слой $p$-Ge, так что дальнейшее уменьшение $L_{n}$ вследствие накопления радиационных дефектов уже не приводит к существенному понижению ФЧ.

Следует отметить также, что изменение спектра ФЧ фотодиода на базе ЭС было неравномерным. Так, после первого облучения (рисунок, $c$, кривая 2) ФЧ в спектральной области 0.8 эВ $<h v<1.2$ эВ уменышилась сильнее, чем при $h v>1.2$ эВ. Данный эффект может быть связан с тем, что, несмотря на значительную толщину ЭС Ge в исследуемых диодах $\sim 1$ мкм, излучение в спектральной области $h v>0.8$ эВ поглощается в слое $\mathrm{Ge}$ не полностью. Так, при $\alpha \sim 10^{4} \mathrm{~cm}^{-1}$ для прямых межзонных оптических переходов в $\mathrm{Ge}$ [5] интенсивность излучения уменьшается в $е$ раз при прохождении через слой $\mathrm{Ge}$ толщиной 1 мкм, так что ФЧ в спектральной области $h v>E_{g \mathrm{Si}} \sim 1.12$ эВ частично обусловлена межзонным поглощением в буферном слое $n^{+}$-Si c последующей диффузией неосновных носителей (дырок) к границе ОПЗ гетероперехода $n^{+}-\mathrm{Si} / p-\mathrm{Ge}$. C увеличением дозы облучения длина диффузии дырок в $\mathrm{Si} L_{p}$ также уменьшается, что приводит к уменьшению ФЧ диода в спектральной области собственного поглощения $\mathrm{Si}$. 


\section{4. Заключение}

Проведенные экспериментальные исследования показали отсутствие деградации ФЧ $p-n$-фотодиодов на базе $\mathrm{Si}$ с наноостровками $\mathrm{GeSi}$ в активной области под действием импульсного $\gamma$-нейтронного облучения в спектральной области межзонного оптического поглощения островков $\mathrm{GeSi}$, которое можно связать с пространственной локализацией процесса фотогенерации носителей заряда в наноостровках $\mathrm{GeSi}$, расположенных в ОПЗ $p-n$-перехода. В то же время с ростом флюенса и дозы облучения обнаружено монотонное ослабление фотоотклика в области собственного поглощения $\mathrm{Si}$, а также по всему спектру $Ф Ч$ фотодиодов на базе ЭС $\mathrm{Ge} / \mathrm{Si}(001)$ вследствие уменьшения времени жизни неосновных носителей заряда в $\mathrm{Si}$ и $\mathrm{Ge}$ соответственно, вызванного появлением под воздействием облучения дополнительных рекомбинационных центров. Данный результат может быть использован при разработке технологии изготовления радиационно стойких фотоприемников на основе Si с расширенным спектральным диапазоном в ИК-область, которые могут быть использованы, в частности, в оптических межэлементных соединениях, оптронах, оптопарах и оптических развязках.

Работа выполнена в рамках государственного задания № 16.7443.2017/БЧ Министерства образования и науки РФ.

\section{Список литературы}

[1] R. Leon, G.M. Swift, B. Magness, W.A. Taylor, Y.S. Tang, K.L. Wang, P. Dowd, Z.-Y. Zhang. Appl. Phys. Lett., 76, 2074 (2000).

[2] M.B. Huang, J. Zhu, S. Oktyabrsky. Nucl. Instrum. Meth. B, 211, 505 (2003).

[3] А.В. Новиков, А.Н. Яблонский, В.В. Платонов, С.В. Оболенский, Д.Н. Лобанов, З.Ф. Красильник. ФТП, 44, 346 (2010).

[4] З.Ф. Красильник, К.Е. Кудрявцев, А.Н. Качемцев, Д.Н. Лобанов, А.В. Новиков, С.В. Оболенский, Д.В. Шенгуров. ФТП, 45, 230 (2011).

[5] J. Wang, S. Lee. Sensors, 11, 696 (2011).

[6] В.Г. Шенгуров, В.Ю. Чалков, С.А. Денисов, С.П. Светлов, Д.В. Шенгуров. Вакуумная техника и технология, 21, 45 (2011).

[7] D.O. Filatov, M.A. Isakov, V.G. Shengurov, M.O. Marychev, A.V. Nezdanov, A.I. Mashin. In: Photoluminescence: Applications, Types and Efficacy, ed. by M.A. Case, B.C. Stout (N. Y., Nova Science, 2012) p. 1.

[8] Д.О. Филатов, М.В. Круглова, М.А. Исаков, М.О. Марычев, В.Г. Шенгуров, В.Ю. Чалков, С.А. Денисов. ФТП, 42 , 1116 (2008).

[9] C. Mukherjee, H. Seitz, B. Schröder. Appl. Phys. Lett., 78, 3457 (2001).

[10] В.Г. Шенгуров, В.Ю. Чалков, С.А. Денисов, Н.А. Алябина, Д.В. Гусейнов, В.Н. Трушин, А.П. Горшков, Н.С. Волкова, М.М. Иванова, А.В. Круглов, Д.О. Филатов. ФТП, 49, 1411 (2015).
[11] Д.О. Филатов, А.П. Горшков, Н.С. Волкова, Д.В. Гусейнов, Н.А. Алябина, М.М. Иванова, В.Ю. Чалков, С.А. Денисов, В.Г. Шенгуров. ФТП, 49, 399 (2015).

[12] G.G. Macfarlane, T.P. McLean, J.E. Quarrington, V. Roberts. J. Phys. Chem. Solids, 8, 388 (1959).

[13] T.S. Moss. J. Elect. Control, 1, 126 (1955).

[14] А.В. Скупов. ФТП, 49, 634 (2015).

[15] Y.C. Chen, J. Singh, P.K. Bhattacharya. J. Appl. Phys., 74, 3800 (1993).

Редактор А.Н. Смирнов

\section{Effect of pulsed gamma-neutron irradiation on the photosensitivity of the Si-based photodiodes with the GeSi nanoislands and AGe epitaxial layuers}

M.M. Ivanova ${ }^{1,2}$, A.N. Kachemtsev ${ }^{2}$, A.N. Mikhaylov², D.O. Filatov ${ }^{2}$, A.P. Gorshkov ${ }^{2}$, N.S. Volkova ${ }^{2}$, V.Yu. Chalkov², V.G. Shengurov ${ }^{2}$

${ }^{1}$ Sedakov Research Institute of Measuring Systems, 603950 Nizhny Novgorod, Russia

${ }^{2}$ Lobachevskii State University of Nizhny Novgorod, 603950 Nizhny Novgorod, Russia

Abstract The results of a comparative study of the effect of the pulsed $\gamma$-neutron irradiation on the photosensitivity (PS) spectra of the Si $p-n$-photodiodes with the active layers based on the selfassembled GeSi nanoisland arrays and on the Ge epilayers (ELs) are presented. The irradiation of the photodiodes with the GeSi nanoislands has been found not to result in the degradation of the PS in the spectral band of the interband optical absorption in the nanoislands (the wavelength band $1.1-1.7 \mathrm{mkm}$ ). At the same time, a monotonous decrease of the intrinsic PS of $\mathrm{Si}$ as well as of the PS of the photodiodes based on the Ge ELs with increasing irradiation dose has been observed. The effect was attributed to the accumulation of the radiation defects in the $\mathrm{Si}$ matrix and in the Ge ELs, respectively. 